\title{
Factors affecting surface management of dental unit chair.
}

\author{
Jung-Ok Choi ${ }^{1}$, Yu-Hee Lee ${ }^{2}$, Seoul-Hee Nam ${ }^{3 *}$ \\ ${ }^{1}$ Department of Dental Hygiene, Youngsan University, Yangsan, Republic of Korea \\ ${ }^{2}$ Department of Dental Hygiene, Taegu Science University, Taegu, Republic of Korea \\ ${ }^{3}$ Department of Dental Hygiene, College of Health Science, Kangwon National University, Samcheok-si, Republic of \\ Korea
}

\begin{abstract}
The purpose of this study was to analyze factors affecting unit chair surface management to prevent cross infection of dental hygienist. A total of 311 dental hygienists were surveyed and received general characteristics and responses to dental infection characteristics. The surface of the unit chair was divided into 5 parts and the items for each management method were examined. The statistical analysis of this study was carried out by correlation analysis and multiple regression analysis using SPSS. According to the results of the study, $94.3 \%$ of the dental hygienists responded that the infection was important and the related education experience was 76.2\%. As for the unit chair management period, the most frequent response was to the start of treatment every day, with $46.6 \%$. The management method was not using disposable cover or disinfectant. The factors influencing the unit chair management were the average number of patients per day, and the bracket table was related to the number of chairs. Control switches were found to be associated with the importance of infection control. In conclusion, although the awareness and practice of infection control is high, it is necessary to improve the method, and it seems that the management of unit chair is insufficient in dental hospitals with many patients and unit chairs. Policy improvement that can be dedicated to infection prevention activities seems to be very necessary.
\end{abstract}

Keywords: Cross infection, Factor, Management, Surface, Unit chair.

Accepted on August 18, 2018

\section{Introduction}

Along with the rapid increase of the social interest in and awareness of the importance of health, problems caused by infections in hospitals have gradually emerged. Particularly, medical staff and patients are exposed to saliva or blood in dental hospitals or clinics due to the nature of their work, and there is a possibility of cross-infection as dental treatment involves procedures that may cause infection, including simple surgical procedures performed in the general treatment room [1-3]. Thus, infection control in dental hospitals is an important task for protecting people's health and for ensuring the safety of the employees. The behaviour's pertaining to such can minimize the incidence of infection and can protect the patients and medical staff.

Cross-infection refers to the transmission of infection-inducing factors between the medical staff and the patient in the treatment room. The main route of transmission is indirect contact with the blood or saliva and the bio-aerosol sprayed into the air through various rotation devices during medical treatment [4]. Life-threatening infections have been known to occur through contact with micro-organisms or organisms, and numerous species of pathogenic microorganisms are constantly evolving. The infectious diseases that cause cross-infection in the treatment room include hepatitis B and C, tuberculosis, and diseases caused by oral infection, and recent studies have also reported HIV infection [5,6]. Staphylococcus aureus, one of the major causes of infection in hospitals, is a gram-positive coccus that causes local and systemic infection through opportunistic infection, which is involved in most pyogenic infections [7]. Therefore, it is known to be deeply involved in endocarditis, bacteremia, and soft-tissue infection, which occur after dental treatment [8-10]. Cross-infection in the dental treatment room can therefore result from various direct and indirect factors. It has been known that cross-infection can be prevented by wearing personal protective equipment, hand washing, disinfection and sterilization of devices and equipment, and waste management.

The largest dental equipment is the unit chair. The unit chair is a complex medical device equipped with the various tools needed for dental treatment, such as hand pieces, scalers, airwater syringes, and the spittoon [11]. Therefore, the unit chair should be treated as important for infection control in the dental treatment room, and the managers of such equipment 
should be made aware of the infection control measures that must be employed in relation to such equipment.

This study aimed to determine the degree of influence of infection control awareness among dental hygienists and the factors affecting the infection control practice for unit chairs so that the study results could be used as fundamental data for efficient dental infection control education programs for hospital employees.

\section{Materials and Methods}

\section{Study subjects}

The study subjects were selected through simple random sampling among the dental hygienists working in the dental institutions in the Busan area in South Korea. A survey was conducted after providing the subjects with sufficient explanations of what the study was about and how it would be conducted, and after obtaining the subjects' study participation consent. A total of 311 questionnaires were used for the final analysis, excluding those with incomplete responses.

\section{Methods of survey}

In this study, seven general characteristics items were examined. To understand the status of the infection control activities in the study area, 8 infection control characteristics items were examined with reference to the dental and medical standard evaluation criteria established by Korea Institute for Health and Social Affairs. To investigate the dental unit chair surface management status, the unit chair was divided into the seat, bracket table, light, switch, and spittoon; whether or not to manage the surface and the surface management methods (use of a disposable cover, use of a surface disinfectant, and use of other methods) were examined.

\section{Statistical analysis}

For the statistical analysis, SPSS ver.22.0 (IBM Corp., Armonk, NY, USA) was used, and the statistical significance was set to $\alpha=0.05$. The subjects' characteristics, the infection control characteristics, and the surface management status of each of the five unit chair parts were analyzed based on descriptive statistics. To identify the factors affecting the unit chair surface management, multiple regression analysis was performed. Correlation analysis was first performed for the unit chair parts, subject characteristics and infection control characteristics and the variables that showed significant correlations were included in the final analysis.

\section{Results}

\section{General characteristics of subjects}

There were 4 males (1.3\%) and 307 females (98.7\%). As for the ages of the subjects, $141(45.3 \%)$ were under $25 \mathrm{y}, 116$ $(37.3 \%)$ were 25 to under $30 \mathrm{y}, 47(15.1 \%)$ were 30 to under 40 $\mathrm{y}$, and $7(2.3 \%)$ were $40 \mathrm{y}$ or older. In terms of the working duration and the highest level of education attained, 196 $(63.0 \%)$ worked for $5 \mathrm{y}$ or less, and $231(74.3 \%)$ had a college diploma.

In terms of the workplace, $164(52.7 \%)$ worked at clinics and $147(47.3 \%)$ worked at hospitals. For the average number of patients per day, $123(39.5 \%)$ had 90 patients or more, 72 $(23.2 \%)$ had $30-60$ patients, $61(19.6 \%)$ had less than 30 patients, and $55(17.7 \%)$ had $60-90$ patients. As for the number of chairs, more than 10 chairs was the most common answer (202 persons, 65.0\%) (Table 1).

Table 1. General and work-related characteristics of subjects.

\begin{tabular}{|c|c|c|}
\hline Variables & Group & N (\%) \\
\hline \multirow{2}{*}{ Sex } & Male & $4(1.3)$ \\
\hline & Female & 307 (98.7) \\
\hline \multirow{4}{*}{ Age } & -25 & $141(45.3)$ \\
\hline & $25-30$ & $116(37.3)$ \\
\hline & $30-40$ & $47(15.1)$ \\
\hline & -40 & $7(2.3)$ \\
\hline \multirow{3}{*}{ Employment period } & -5 & $196(63.0)$ \\
\hline & $5-10$ & $83(26.7)$ \\
\hline & -10 & $32(10.3)$ \\
\hline \multirow{3}{*}{ Education } & Diploma & $231(74.3)$ \\
\hline & Graduate school & $68(21.9)$ \\
\hline & Others & $12(3.9)$ \\
\hline \multirow{2}{*}{ Position } & Dental clinic & $164(52.7)$ \\
\hline & Dental hospital & $147(47.3)$ \\
\hline \multirow{4}{*}{$\begin{array}{l}\text { Average number of } \\
\text { patients per day }\end{array}$} & -30 & $61(19.6)$ \\
\hline & $30-60$ & $72(23.2)$ \\
\hline & $60-90$ & $55(17.7)$ \\
\hline & -90 & $123(39.5)$ \\
\hline \multirow{4}{*}{ Number of chairs } & -3 & $1(0.3)$ \\
\hline & $3-5$ & $54(17.4)$ \\
\hline & $6-10$ & $54(17.4)$ \\
\hline & -10 & $202(65.0)$ \\
\hline \multicolumn{2}{|l|}{ Total } & $311(100.0)$ \\
\hline
\end{tabular}

\section{Infection control characteristics of subjects}

With regard to infection control, 293 (94.3\%) answered that infection control is important, and $282(90.7 \%)$ answered that infection control education is necessary. Meanwhile, the infection control education completion rate was $76.2 \%$ (237 persons). 
In terms of the surface management cycle, $145(46.6 \%)$ answered before the start of treatment every day, followed by the end of treatment every day, per patient, and before and after treatment every day. The most common reason for not managing the surface was the hassle involved (17 persons, $5.5 \%$ ) (Table 2).

Table 2. Infectious control characteristics of subjects.

\begin{tabular}{|c|c|c|}
\hline Variables & Group & $\mathbf{N}(\%)$ \\
\hline \multirow{3}{*}{$\begin{array}{l}\text { Importance of } \\
\text { infection control }\end{array}$} & Not important & $2(0.6)$ \\
\hline & Normal & $16(5.1)$ \\
\hline & Important & $293(94.3)$ \\
\hline \multirow{3}{*}{ Need infection control } & No necessary & $4(1.3)$ \\
\hline & Normal & $25(8.0)$ \\
\hline & Necessary & $282(90.7)$ \\
\hline \multirow{2}{*}{$\begin{array}{l}\text { Infection } \\
\text { education }\end{array}$} & No & $74(23.8)$ \\
\hline & Yes & $237(76.2)$ \\
\hline \multirow{5}{*}{$\begin{array}{l}\text { Surface management } \\
\text { cycle }\end{array}$} & Per patient & $38(12.2)$ \\
\hline & The start of treatment every day & $145(46.6)$ \\
\hline & The end of treatment every day & $81(26.0)$ \\
\hline & before and after treatment every day & $33(10.6)$ \\
\hline & Others & $14(4.5)$ \\
\hline \multirow{2}{*}{$\begin{array}{l}\text { Reason for not } \\
\text { surface management }\end{array}$} & Cost & $1(0.3)$ \\
\hline & Hassle & $17(5.5)$ \\
\hline
\end{tabular}

\begin{tabular}{|c|c|c|}
\hline & No danger & $15(4.8)$ \\
\hline & Long treatment time & $5(1.6)$ \\
\hline & Others & $1(0.3)$ \\
\hline & None & $272(87.5)$ \\
\hline Total & & $311(100.0)$ \\
\hline
\end{tabular}

Values are presented as number (weighted \%); ${ }^{*}$ Calculated by chi-square test.

\section{Surface management practice of dental unit chair}

The unit chair was divided into five parts (the seat, bracket table, light, control switch, and spittoon), and the surface management status of each part was examined. As a result, 300 $(96.5 \%)$ conducted seat surface management. For the management, 183 (58.8\%) used other methods, 98 (31.5\%) used a surface disinfectant, and $53(17.0 \%)$ used a disposable cover. A total of $305(98.1 \%)$ conducted bracket table surface management, with 215 (69.1\%) using other methods, 97 (31.2\%) using a surface disinfectant, and 18 (5.8\%) using a disposable cover. A total of $307(98.7 \%)$ conducted light surface management, with 214 (68.8\%) using other methods, $94(30.2 \%)$ using a surface disinfectant, and $20(6.4 \%)$ using a disposable cover. A total of $289(92.9 \%)$ conducted control switch surface management, with 201 (64.6\%) using other methods, $87(28.0 \%)$ using a surface disinfectant, and 24 (7.7\%) using a disposable cover. Finally, a total of $310(99.7 \%)$ conducted spittoon surface management, with $196(63.0 \%)$ using a surface disinfectant, followed by other methods $(140$ persons, $45.0 \%$ ) and a disposable cover (11 persons, $3.5 \%$ ) (Table 3).

Table 3. Surface management according to unit chair position.

\begin{tabular}{|c|c|c|c|c|c|}
\hline Variables & & No management & Disposable cover & Surface disinfectant & Other methods \\
\hline \multirow{2}{*}{ Seat } & No & $11(3.5)$ & $235(83.0)$ & $213(68.5)$ & $128(41.2)$ \\
\hline & Yes & $300(96.5)$ & $53(17.0)$ & $98(31.5)$ & $183(58.8)$ \\
\hline \multirow{2}{*}{ Bracket table } & No & $6(1.9)$ & $293(94.2)$ & $214(66.8)$ & $96(30.9)$ \\
\hline & Yes & $305(98.1)$ & $18(5.8)$ & $97(31.2)$ & $215(69.1)$ \\
\hline \multirow{2}{*}{ Light } & No & $4(1.3)$ & $291(93.6)$ & $217(69.8)$ & $97(31.2)$ \\
\hline & Yes & $307(98.7)$ & $20(6.4)$ & $94(30.2)$ & $214(68.8)$ \\
\hline \multirow{2}{*}{ Control switch } & No & $22(7.1)$ & $287(92.3)$ & $224(72.0)$ & $110(35.4)$ \\
\hline & Yes & $289(92.9)$ & $24(7.7)$ & $87(28.0)$ & $201(64.6)$ \\
\hline \multirow{2}{*}{ Spittoon } & No & $1(0.3)$ & $300(96.5)$ & $115(37.0)$ & $171(55.0)$ \\
\hline & Yes & $310(99.7)$ & $11(3.5)$ & $196(63.0)$ & $140(45.0)$ \\
\hline
\end{tabular}

Values are presented as number (weighted \%); ${ }^{*}$ Calculated by multiple logistic regression analysis

\section{Seat management of dental unit chair related factors}

After the correlation analysis between the variables of general and infection characteristics and seat management, the influences of the significantly correlated variables (working duration, average number of patients per day, and number of chairs on seat management) were analyzed. The average 
number of patients per day was found to be significantly related to seat management $(\mathrm{p}<0.008)$ (Table 4$)$.

Table 4. Factor analysis on seat management of dental unit chair.

\begin{tabular}{lllll}
\hline Variables & $\boldsymbol{\beta}$ & $\mathbf{S . E}$ & $\mathbf{t}$ & $\mathbf{p}$ \\
\hline Employment period & -0.006 & 0.016 & -0.1 & 0.92 \\
\hline Number of patients & 0.191 & 0.011 & 2.673 & 0.008 \\
\hline Number of chairs & 0.039 & 0.017 & 0.543 & 0.587 \\
\hline
\end{tabular}

$F=5.134, p<0.001 ; R^{2}=0.048, \operatorname{Adj} R^{2}=0.038$; By multiple regression analysis

\section{Bracket table management of dental unit chair related factors}

After the correlation analysis between the variables of general and infection characteristics and bracket table management, the influences of the significantly correlated variables (working duration, average number of patients per day, and number of chairs on bracket table management) were analyzed. The number of chairs was found to be significantly related to bracket table management $(\mathrm{p}<0.003)$ (Table 5).

Table 5. Factor analysis on bracket table management of dental unit chair.

\begin{tabular}{lllll}
\hline Variables & $\boldsymbol{\beta}$ & $\mathbf{S . E}$ & $\mathbf{t}$ & $\mathbf{p}$ \\
\hline Employment period & 0.012 & 0.011 & 0.212 & 0.832 \\
\hline Number of patients & 0.082 & 0.008 & 1.164 & 0.245 \\
\hline Number of chairs & 0.214 & 0.012 & 3.029 & 0.003 \\
\hline
\end{tabular}

$F=8.074, p<0.001 ; R^{2}=0.073$, Adj $R^{2}=0.064 ;$ By multiple regression analysis.

\section{Lighting management of dental unit chair related factors}

After the correlation analysis between the variables of general and infection characteristics and unit chair light management, the influences of the significantly correlated variables (average number of patients per day and number of chairs on light management) were analyzed. The variables did not show a significant influence (Table 6).

Table 6. Factor analysis on lighting management of dental unit chair.

\begin{tabular}{lllll}
\hline Variables & $\boldsymbol{\beta}$ & $\mathbf{S . E}$ & $\mathbf{t}$ & $\mathbf{p}$ \\
\hline Number of patients & 0.14 & 0.007 & 1.951 & 0.052 \\
\hline Number of chairs & 0.054 & 0.01 & 0.751 & 0.453 \\
\hline
\end{tabular}

$F=5.067, p<0.001 ; R^{2}=0.032$, Adj $R^{2}=0.026$; By multiple regression analysis.

\section{Control switch management of dental unit chair related factors}

After the correlation analysis between the variables of general and infection characteristics and unit chair control switch management, the influence of a significantly correlated variable-the importance of infection control-on unit chair control switch management was analyzed. The importance of infection control was found to be significantly related to unit chair control switch management $(p<0.003)$ (Table 7).

Table 7. Factor analysis on control switches management of dental unit chair.

\begin{tabular}{lllll}
\hline Variables & $\boldsymbol{\beta}$ & S.E & $\mathbf{t}$ & $\mathbf{p}$ \\
\hline Importance of infection control & 0.166 & 0.053 & 2.966 & 0.003 \\
\hline
\end{tabular}

$F=8.797, p<0.001 ; R^{2}=0.028$, Adj $R^{2}=0.025$; by multiple regression analysis.

\section{Discussion}

Since recently, many dental hospitals and clinics have made much effort to prevent cross-infection. In reality, however, perfect infection prevention is difficult, and the infection management method needs to be unified because it varies according to the treatment room or manager. In particular, the unit chair, the largest equipment in the treatment room, is essential equipment for patient care. Thus, this study was conducted to analyze the various factors affecting the management of the unit chair, and to use the study results for infection prevention.

For the general characteristics of the subjects, the largest proportion of the subjects $(82.6 \%)$ were in their $20 \mathrm{~s}$, and $63.0 \%$ had $5 \mathrm{y}$ or less working experience. The age and working duration of the dental hygienists were similar to those in most other studies on the same population. The reason for this seems to be that dental hygienists have a relatively large number of work alternatives that they can consider, and getting a job is relatively easy. Thus, it can be understood as a job nature of dental hygienists [12-14]. The most common workplace was the dental clinic (52.7\%), and the most common average number of patients per day was 90 patients or more $(39.5 \%)$. The number of patients in this study was higher than that in the previous studies $[12,15]$. It is important to note that the proportion of dental diseases in the most common diseases has been increasing of late [16], which seems to result in the increase in the number of dental patients and the disproportion between the number of dental patients and the size of the dental hospital or clinic. This may lead to the neglect of infection control.

As a result of the analysis of infection control awareness among the study subjects, $94.3 \%$ answered that it is important, and $90.7 \%$ answered that infection education is necessary. In the study conducted by Jung et al. [17], 91.9\% of the subject dental hygienists answered that infectious disease awareness is important, which was similar to the result of the present study. Infection prevention can start from infection control awareness. For the necessity of infection education, the study conducted by Jung et al. [17] showed a similar result (97.3\%) while another study showed somewhat lower result (55.9\%) [18]; although these studies did not provide a specific reason for this, the reason seems to be that their subjects had experienced overly simplistic and uninteresting education in the past. To 
improve this, it is necessary to change people's perception of the necessity of infection education, showing them that it has a positive effect on infection prevention through repeated and practical education using various educational materials and forms, such as continuing education.

The infection education completion rate related to the infection was found to be $76.2 \%$ in this study, indicating that the implementation rate was somewhat lower compared to the necessity of such education. This was similar to the results of other studies, and staff training or continuing education within the dental hospital or clinic was utilized $[19,20]$.

According to the results of the survey on the surface management of the unit chair seat, bracket table, dental light, and control switch, which are the most frequently used parts of the unit chair, most of the subjects were conducting surface management for them, but the effectiveness and efficiency of their management methods have not been verified. McColl et al. [21] mentioned that one of the most contaminated surfaces in the treatment room after general treatment is the light handle of the unit chair. The generation of aerosol in dental hospitals or clinics where treatment procedures using the spraying power of compressed air are frequently performed contaminates the surfaces of devices and equipment, which leads to secondary infection. In addition, contaminated surfaces also become a pathway of infection transmission. As such, the surface management of the unit chair, which is easy to overlook, can directly or indirectly have a significant impact on infection, and effective management methods need to be actively utilized. As the surface of the unit chair cannot be sterilized, however, it is necessary to disinfect it using an appropriate method. In this case, the types of disinfectant that can be typically used are products containing alcohol, aldehyde, phenol, halogen compound, etc. [22,23]. Alternatively, a surface cover may be utilized.

Many dental hygienists have reported, however, that they are not performing unit chair surface management properly due to problems such as limited time and manpower. With regard to the factors affecting the surface management of the unit chair for infection control, the seat management was found to be significantly associated with the average number of patients per day, and the bracket table management was found to be significantly associated with the number of chairs. The surface management of the unit chair in the treatment room for infection control was thus correlated with the number of patients and the size of the dental hospital or clinic. As this can be interpreted as an increase in the roles of the dental hygienists in the hospital, there seem to be difficulties in managing the unit chair. This interpretation conflicts with the appointment of an infection control manager, which is a requirement for effective infection control, because even if such a manager is appointed, he or she is to hold multiple positions, not only that of infection control manager, and the proportion of his or her other tasks is relatively higher [24-26].

This study was conducted for the dental hygienists only in a certain region; thus, there is a limitation in generalizing the results to all dental hygienists. Moreover, the institutional necessity of infection control management according to the size of the hospital was not considered, and the relevant factors were analyzed using only a questionnaire, not based on a scientific experiment.

\section{Conclusion}

This study was conducted to emphasize the importance of management activities to prevent infections with the increased interest in the risk of infection, and to provide fundamental data for considering effective and systematic management measures through the management of the unit chair, which is the largest equipment in the treatment room. In conclusion, although dental hygienists have a high level of infection control awareness and practice, unit chair surface management is actually not being implemented in a proper way. Therefore, systematic education and related guidelines should be prepared. In addition, institutional arrangements are needed to encourage active participation in infection control activities.

\section{Acknowledgment}

This work was supported by Youngsan University Research Fund of 2018.

\section{Conflict of Interest}

The authors report no conflicts of interest related to this study. The author does not have any financial interest in the companies whose materials are included in the article.

\section{References}

1. Lee JY, Jeong MK. A study on recognition and practice of dental hygiene students for Infection control dental hygiene major courses. J Korean Soc Dent Hyg 2009; 9: $73-88$

2. Song KH, Bae BJ. A study on Hepatitis B and knowledge about AIDS of dental hygiene student in Korea. J Korean Soc Dent Hyg 2001; 1: 181-192.

3. Ryu MH. Cross-infection $\mathrm{n}$ dental clinic and infection control. J Namseoul Univ 2005; 11: 157-172.

4. Chung WG, Yoo JH, Kim NH, Lim HK. The patient's perception of wearing personal protective equipment in dental health-care settings. JKAOH 2009; 33: 441-450.

5. Centers for Disease Control and Prevention. Guidelines for infection control in dental healthcare settings. Recommendations and Reports 2003; 52: 1-61.

6. Jamshid A, Fatemah A, Ali MA, Rezvan B, Jahangir A, Ali A, Mohammad BO. Occupational hazards to dental staff. Dent Res J 2012; 9: 2-7.

7. Mun SE, Lee DG, Kwon GH, Kim GJ. Infection pattern of Staphylococcus aureus in the dental clinic. Maxillofac Plast Reconstr Surg 2003; 25: 25-32.

8. Etienne J, Fleurette J, Ninet, JF, Favet P, Gruer LD. Staphylococcal endocarditis after dental extraction. Lancet 1986; 30: 511-512. 
9. Etienne J, Brun Y, Fleurette J. Staphylococcus lugdunensis endocarditis. J Clin Pathol 1989; 42: 892-893.

10. Freney J, Brun Y, Bes M, Meugnier H, Grimont F, Grimont PAD, Nervi C, Fleurette J. Staphylococcus lugdunensis sp. nov. and Staphylococcus schleiferi sp. nov., two species from human clinical specimens. Int $\mathbf{J}$ Syst Evol Microbiol 1988; 38: 168-172.

11. Wi JH. A study on the design direction of the dental unit chair through the design satisfaction. KICD 2017; 51: 121-131.

12. Lee YH, Choi SM. The cognition and practice of infection control in dental workplace. J Korean Radiol 2015; 9: 409-416.

13. Kim KY. A study on the impact of psychological empowerment on job attitudes and turnover intention of dental hygienists. KJ-HSM 2010; 4: 1-10.

14. Mobley WH, Griffeth RW, Hand HH, Meglino BM. Review and conceptual analysis of the employee turnover process. Psychol Bulletin 1979; 86: 493-522.

15. Nam YS, Yoo JS, Park MS. A study on actual conditions for prevention of infections by dental hygienist. J Dent Hyg Sci 2010; 34: 187-197.

16. Choi YK, Do SR, Park DY. Change in number of outpatients with periodontal diseases during recent 20 years based on patient survey. JKAOH 2011; 35: 331-339.

17. Jeong MK, Lee JY, Kang YJ. A study on the knowledge and attitude of dental hygienists for infection control in dental clinic. J Korean Soc Dent Hyg 2010; 10: 935-945.

18. Park JH, Heo NS, Song HJ. A study of current infection control by dental hygienists and related factors. J Korean Soc Dent Hyg 2011; 11: 993-1003.

19. Park HS, Choi JY, Sim SH, Kim JS, Choi BK, Jang HK. A study on practice of infection control by dental hygienists-with reference to Seoul and Incheon, Gyeonggi Province. JDHS 2008; 8: 275-281.
20. Lee KY, Lee JA. A research of dental hygienist's recognition on dental infection. J Korean Soc Dent Hyg 2009; 9: 1-17.

21. McColl E, Bagg J, Winning S. The detection of blood on dental surgery surfaces and equipment following dental hygiene treatment. Br Dent J 1994; 176: 65-67.

22. Shin SS, Yang YM, Kim MA, Kim JG, Baik BJ. The effectiveness of clinical sterilization methods in dental air/ water syringes. J Korean Acad Pediatr Dent 2013; 40: 268-273.

23. Lakeshman S. Essential microbiology for dentistry. Churchill Livingstone, Edinburgh 2007; 314-328.

24. Haley RW, Morgan WM, Culver DH, White JW, Emori TG, Mosser J, Hughes JM. Update form the SENIC project. Hospital infection control: recent progress and opportunities under prospective payment. Am J Infect Control 1985; 13: 97-108.

25. Emori TG, Haley RW, Stanley RC. The infection control nurse in US hospitals, 1976-1977: characteristics of the position and its occupant. Am J Epidemiol 1980; 111: 592-607.

26. Garner JS, Jarvis WR, Emori TG, Horan TC, Hughes JM. CDC definitions for nosocomial infections. Am J Infect Control 1988; 16: 128-140.

\section{*Correspondence to}

Seoul-Hee Nam

Department of Dental Hygiene

College of Health Science

Kangwon National University

Samcheok-si

Republic of Korea 